\title{
PERANCANGAN SISTEM IDENTIFIKASI TIPE SIDIK JARI MANUSIA MENGGUNAKAN MATLAB
}

\author{
Fitri Rahmah \\ Program Studi Teknik Fisika, Fakultas Teknik dan Sains, Universitas Nasional \\ fitri.rahmah@civitas.unas.ac.id
}

Submitted November 17, 2021; Revised December 4, 2021; Accepted December 4, 2021

\begin{abstract}
Abstrak
Sidik jari manusia di dunia ini berbeda antara satu dengan yang lainya. Hal inilah yang menyebabkan sidik jari manusia digunakan sebagai salah satu alat identifikasi atau pengenalan diri. Tipe sidik jari manusia digolongkan menjadi tiga macam, yaitu tipe whorl, arch dan loop. Tranformasi wavelet digunakan karena metode pengolahan citra ini mampu mengidentifikasi garis-garis yang tidak kontinu. Sidik jari manusia mempunyai garis-garis yang tidak kontinu sehingga metode ini baik digunakan untuk mengenali citra sidik jari yang kemudian dibandingkan dengan citra pada database. Selanjutnya dengan metode pengolahan citra dengan software Matlab dan integrasi dengan GUI (Graphic User Interface) sehingga dapat digunakan untuk mengenali tipe sidik jari pada manusia.
\end{abstract}

Kata Kunci : Citra Digital, RGB, Grayscale, Sidik Jari, Transformasi Wavelet

\begin{abstract}
Human fingerprints are unique in this world. This is why human fingerprints are frequently used as a form of identification or self-recognition. Human fingerprints are classified into three categories: whorl, arch, and loop. The wavelet transformation is used because it is capable of identifying discontinuous lines. Because human fingerprints contain discontinuous lines, this method is ideal for recognizing fingerprint images, which are then compared to database images. Additionally, the method of image processing with Matlab software and integration with a GUI (Graphical User Interface) is described, so that it can be used to recognize human fingerprint types.
\end{abstract}

Key Words : Digital Image, RGB, Grayscale, Fingerprint, Wavelet Transform

\section{PENDAHULUAN}

Seiring perkembangan teknologi informasi, banyak diciptakan alat untuk membantu proses identifikasi sidik jari, salah satunya adalah scanner. Scanner merupakan alat yang tepat jika digunakan untuk pengambilan sampel secara langsung. Akan tetapi kurang efektif jika digunakan untuk pengambilan sampel secara tidak langsung. Oleh karena itu kami melakukan studi untuk menghasilkan alat yang dapat mengidentifikasi tipe sidik jari menggunakan pengolahan citra berbasis transformasi wavelet. Namun sebelumnya, sidik jari tersebut harus diubah ke dalam format citra digital agar dapat diolah dengan menggunakan software Matlab.
Perbaikan kualitas citra menggunakan Matlab telah dilakukan pada referensi [1][2]. Citra digital sama pentingnya dengan sistem pembentuk citra digital itu sendiri. Sebuah citra digital dapat dianggap sebagai matriks yang besar dengan titik-titik bernilai diskrit. Masing-masing titik memiliki nilai yang merepresentasikan kecerahan. Titik-titik ini disebut elemen citra, atau biasa disebut piksel. Piksel menunjukkan koordinat dalam citra dan dapat dinyatakan dalam indeks $x$ dan $y$ [3]. Citra digital dapat digolongkan dalam beberapa jenis. Jenis yang pertama yaitu citra warna (true color). Citra warna telah ditetapkan ke nilai bilangan digital yang mewakili rentang spektral sebenarnya dari warna yang digunakan dalam citra yaitu warna merah, hijau, dan biru [4]. 
Jenis citra digital kedua adalah citra keabuan (grayscale). Citra keabuan disimpan dalam format skala keabuan dengan rentang warna yang bervariasi dari hitam ke putih dengan banyak gradasi keabuan. Objek dalam tampilan keabuan memiliki nilai kecerahan yang mewakili tingkat energi terukur dari objek tersebut. Citra keabuan berisi 8 bit/piksel sehingga memungkinkan gambar untuk mewakili (0255) tingkat keabuan yang berbeda [5].

Jenis citra ketiga yaitu citra biner. Pada citra biner merupakan jenis yang paling sederhana karena citra hanya memiliki nilai hitam dan putih atau 0 dan 1 . Citra biner berisi $1 \mathrm{bit} /$ piksel karena hanya hanya dibutuhkan satu digit biner untuk mewakili masing-masing piksel [5].

Pola sidik jari menurut sistem Galton dibedakan menjadi tiga, yaitu arch, loop, dan whorl. Pada pola arch terdapat garis lengkung sejajar menyerupai busur dan datang dari satu sisi kemudian naik di bagian tengah, dan menuju ke sisi yang lain. Pola loop memiliki bentuk garis lengkung seperti kait dengan lebih dari satu garis dating dari sisi yang lain. Selanjutnya pada pola whorl memiliki garis dengan formasi membentuk lingkaran [6].

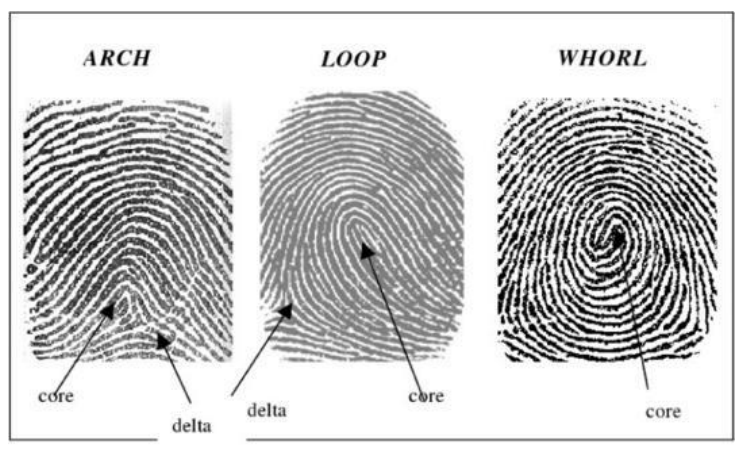

Gambar 1. Tipe Sidik Jari

Transformasi wavelet didasarkan pada gelombang yang sangat kecil, dengan frekuensi yang bervariasi dan waktu yang terbatas. Transformasi wavelet mampu membawa informasi frekuensi dan spasial pada sebuah citra digital. Citra sidik jari yang diproses dengan wavelet menghasilkan multiresolusi dari citra aslinya, sehingga menghasilkan output yang baik [7].

Principal Componen Analysis (PCA) merupakan sebuah metode untuk mengidentifikasi pola pada data dan selanjutnya menampilkan data tersebut ke bentuk yang lain untuk menunjukkan perbedaan dan persamaan antar pola [8].

\section{METODE PENELITIAN}

Prosedur yang dilakukan untuk identifikasi citra sidik jari adalah sebagai berikut:

1. Mengambil citra sidik jari secara langsung menggunakan stamp ink.

2. Hasil gambar sidik jari diletakkan pada kertas putih kemudian dikonversikan menjadi citra digital dengan webcam.

3. Citra hasil foto diolah menggunakan software Matlab menggunakan dua metode yaitu secara manual untuk mengetahui proses pengolahan citranya dan metode GUI yang secara langsung dapat menampilkan gambar.

4. Pada metode manual, dilakukan Langkah sebagai berikut:

- Citra hasil foto webcam .bmp dimasukkan pada listing program pada Matlab

- Mengubah citra digital RGB menjadi citra grayscale menggunakan metode threshold

- Mentransformasi citra grayscale menjadi citra wavelet

- Citra sidik jari wavelet tersebut kemudian disimpan pada database sidik jari yang dipisahkan menjadi dua, yaitu training set sebagai data acuan dan testing set sebagai data yang akan diidentifikasi.

- Untuk mengenali data sidik jari yang sudah tersimpan, maka digunakan citra digital wavelet yang akan diidentifikasi. Data sidik jari yang sudah tersimpan dibandingkan dengan citra sidik jari yang akan diidentifikasi 
menggunakan PCA. Setelah dibandingkan maka akan muncul keputusan yang menentukan nama tipe dari sidik jari tersebut.

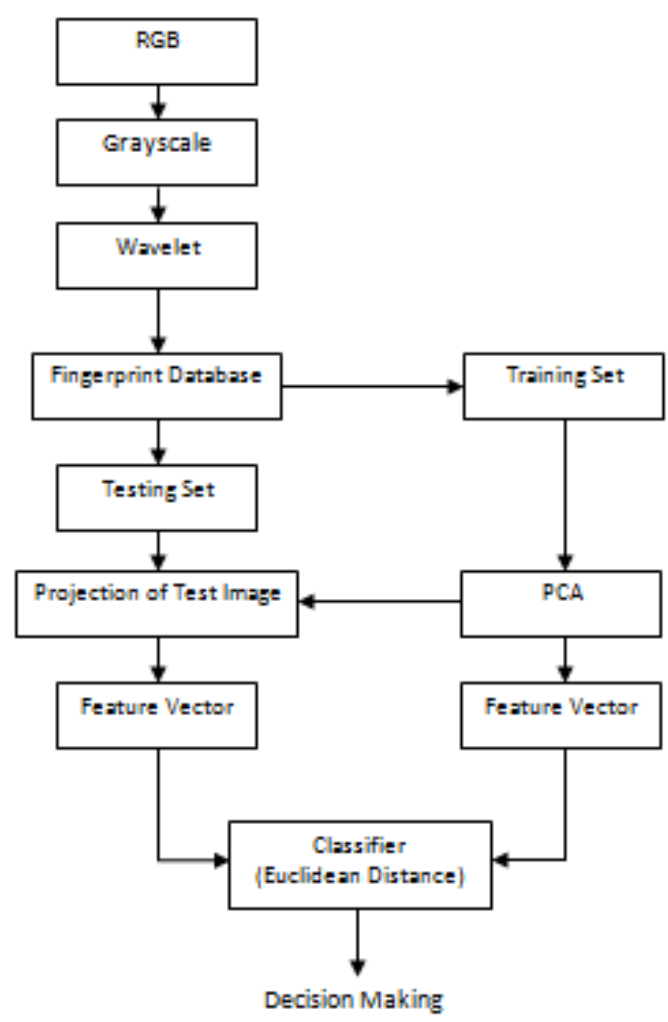

Gambar 2. Diagram Alir Percobaan

5. Selanjutnya menggunakan metode otomatis dengan bantuan GUI (Graphic User Interface) pada Matlab, yaitu dengan:

- Membuka tools GUI pada wavelet

- Memasukkan listing program yang sudah dikerjakan

- Mengunggah citra sidik jari yang sudah difoto menggunakan webcam dimuat pada tools load image

- Setelah gambar masuk pada program GUI, selanjutnya pilih Recognized dan akan muncul hasil pengolahan citra untuk mengenali tipe sidik jari

\section{HASIL DAN PEMBAHASAN}

Percobaan dengan GUI (Graphic User Interface)

Pada saat dilakukan fingerprint recognition menggunakan software Matlab, tampilan GUI ditunjukkan pada Gambar 3-6 .

finger print recognizer

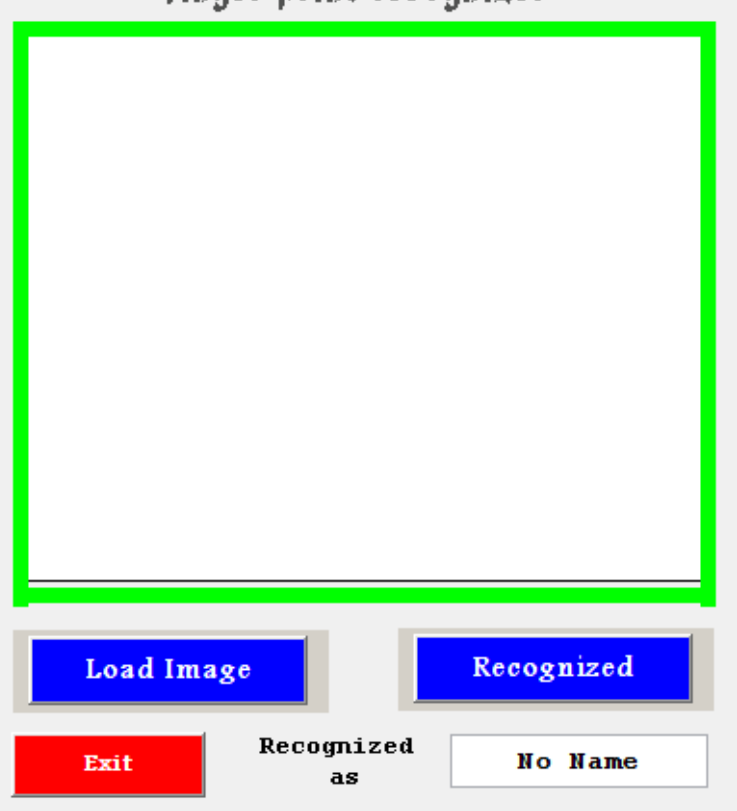

Gambar 3. GUI Identifikasi Citra Sidik Jari

Pada Gambar 3 menunjukkan tampilan GUI Matlab yang terdiri dari beberapa push button antara lain:

- Load Image button untuk unggah citra sidik jari,

- Recognized button untuk memproses citra sidik jari

- Exit button untuk keluar dari tampilan GUI Matlab

- Fingerprint recognizer display untuk menampilkan gambar sidik jari yang diunggah

- Recognized as untuk menampilkan tipe sidik jari

Selanjutnya pada Gambar 4-6 menunjukkan hasil pengenalan tipe sidik jari masing-masing yaitu Arch, Loop, dan Whorl. 
Tabel 1. Data Percobaan Kecocokan Deteksi untuk Semua Citra Sidik Jari

\begin{tabular}{|c|c|c|}
\hline Tipe & Nama File & Status Deteksi \\
\hline \multirow{6}{*}{ Arch } & $a-1$ & Terdeteksi \\
\hline & $a-2$ & Terdeteksi \\
\hline & $a-3$ & Terdeteksi \\
\hline & $a-4$ & Terdeteksi \\
\hline & $a-5$ & Terdeteksi \\
\hline & $a-6$ & Tidak \\
\hline \multirow{10}{*}{ Loop } & $1-1$ & Terdeteksi \\
\hline & $1-2$ & Terdeteksi \\
\hline & $1-3$ & Terdeteksi \\
\hline & $1-4$ & Terdeteksi \\
\hline & $1-5$ & Terdeteksi \\
\hline & $1-6$ & Terdeteksi \\
\hline & $1-7$ & Terdeteksi \\
\hline & $1-8$ & Tidak \\
\hline & $1-9$ & Terdeteksi \\
\hline & $1-10$ & Tidak \\
\hline \multirow{13}{*}{ Wohrl } & $\mathrm{w}-1$ & Terdeteksi \\
\hline & $\mathrm{w}-2$ & Terdeteksi \\
\hline & $w-3$ & Terdeteksi \\
\hline & $w-4$ & Terdeteksi \\
\hline & $w-5$ & Terdeteksi \\
\hline & $w-6$ & Terdeteksi \\
\hline & $w-7$ & Terdeteksi \\
\hline & $\mathrm{w}-8$ & Tidak \\
\hline & $w-9$ & Terdeteksi \\
\hline & $\mathrm{w}-10$ & Tidak \\
\hline & w-11 & Tidak \\
\hline & w-12 & Tidak \\
\hline & $\mathrm{w}-13$ & Tidak \\
\hline
\end{tabular}

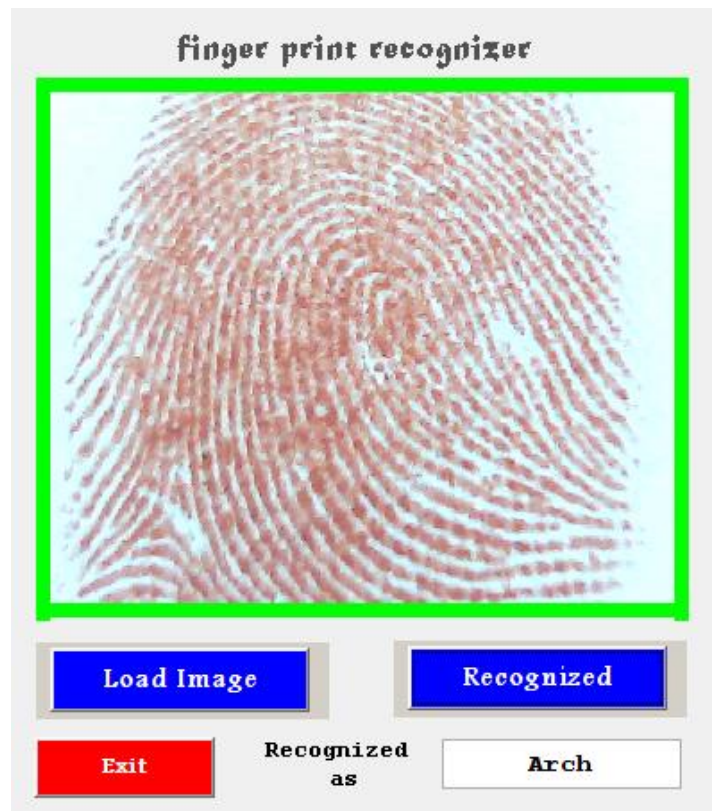

Gambar 4. Load Image untuk Arch-2

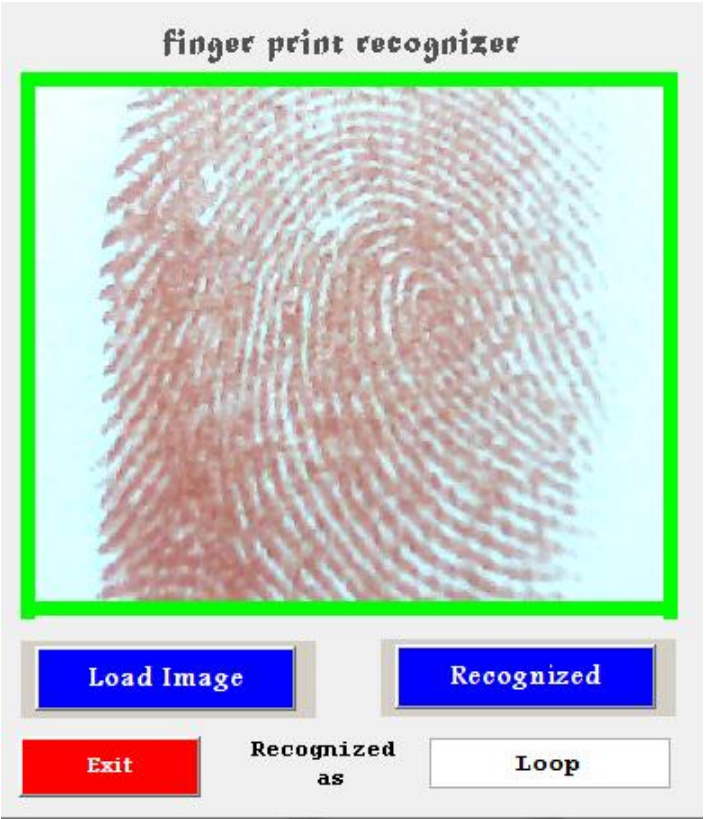

Gambar 5. Load Image untuk Loop-3

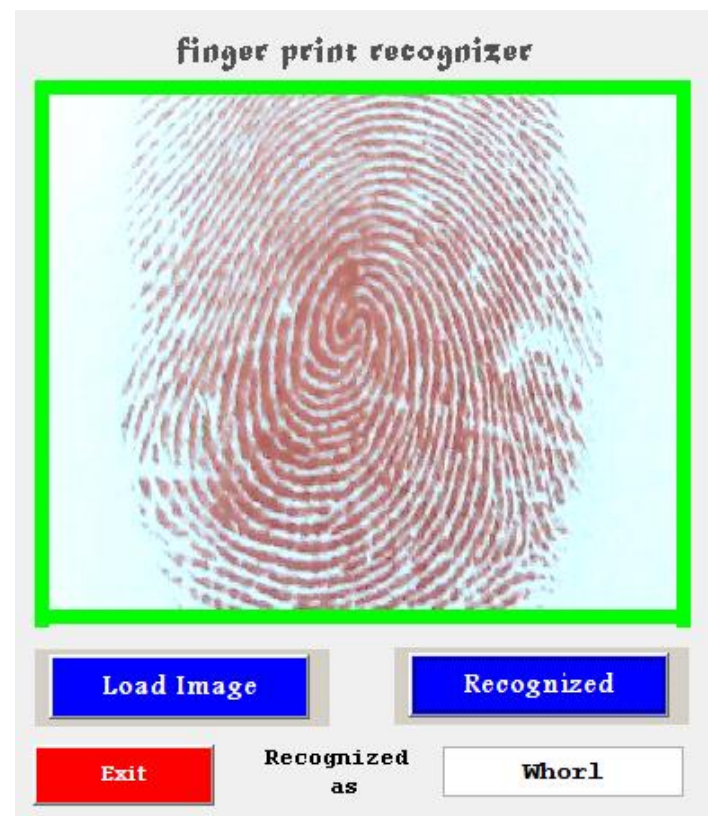

Gambar 6. Load Image untuk Whorl-1

Pada studi ini dilakukan identifikasi citra sidik jari berbasis transformasi wavelet dengan metode PCA (Principle Component Analysis) untuk mengetahui jenis sidik jari sesorang. Terdapat dua model running yaitu yang pertama dengan menggabungkan perangkat GUI (Graphic User Interface) pada Matlab sehingga pengguna hanya perlu untuk melakukan 
load image dari kotak dialog yang muncul dan melakukan perintah recognized.

Tabel 1 menunjukkan hasil pengujian 29 citra sidik jari. Berdasarkan 29 sampel yang diuji, terdapat 8 citra yang tidak berhasil terdeteksi saat dilakukan pengenalan oleh perangkat lunak ini. 8 citra tersebut adalah 1 buah citra dari jenis Arch, 2 buah citra dari jenis Loop, dan 5 buah citra dari jenis Worhl. Kesalahan ini dapat terjadi akibat beberapa faktor. Salah satunya dikarenakan kualitas citra yang kurang baik, dimana citra input terbilang blur sehingga perangkat lunak mengalami kesulitan dalam mendeteksi citra sidik jari tersebut. Sementara yang kedua adalah pola sidik jarinya memang sedikit unik dan berbeda, sehingga terjadi error pada saat pengenalan.

\section{Percobaan dengan Metode Manual}

Selanjutnya adalah melakukan identifikasi citra sidik jari dengan metode manual, dimana pengguna harus memasukkan nama file satu persatu di dalam syntax code. Tujuan dari metode manual ini adalah agar pengguna dapat mengetahui tahapan-tahapan dalam pemrosesan citra dengan menggunakan transformasi wavelet. Hasil output yang didapat adalah beragam gambar citra, yaitu dari citra dalam format RGB, kemudian hasil citra dalam format grayscale, dan selanjutnya gambar citra hasil transformasi wavelet.

Berdasarkan citra ini kemudian muncul juga histogram dari citra itu sendiri, sehingga pengguna dapat menganalisis seperti apakah tampilan wavelet citra beserta figure yang dihasilkan. Metode manual adalah melakukan identifikasi di mana proses wavelet terjadi dan seperti apa tampilan citranya pada saat dilakukan transformasi wavelet. Hasil pada file 1-1 (Loop) ditampilkan pada Gambar 7-10 .

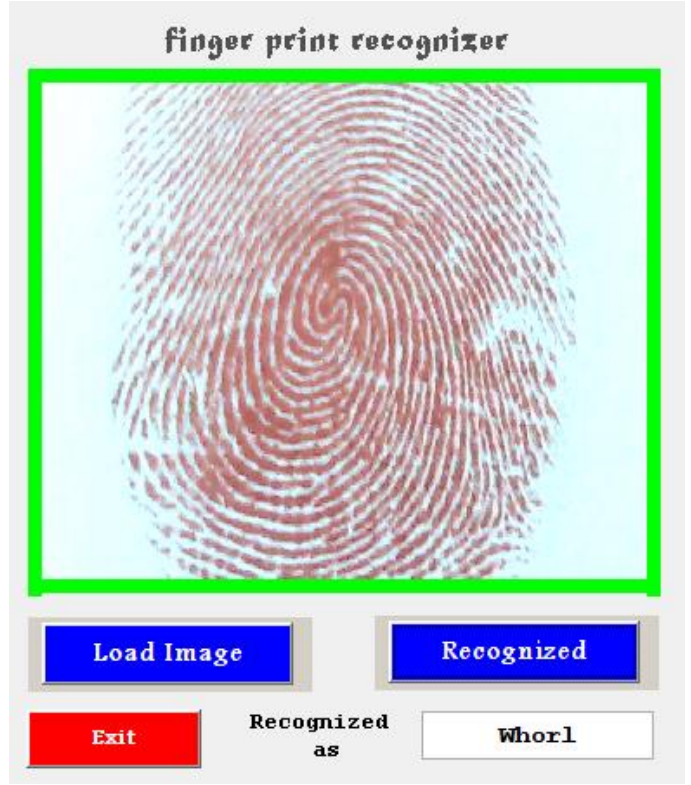

Gambar 7. Citra Input Berupa Citra RGB

Gambar 7 menunjukkan input citra dalam domain RGB dan ditampilkan pada display di fingerprint recognizer. Selanjutnya citra tersebut diolah menjadi bentuk citra Grayscale. Gambar 8 menunjukkan citra sidik jari dalam format Grayscale.

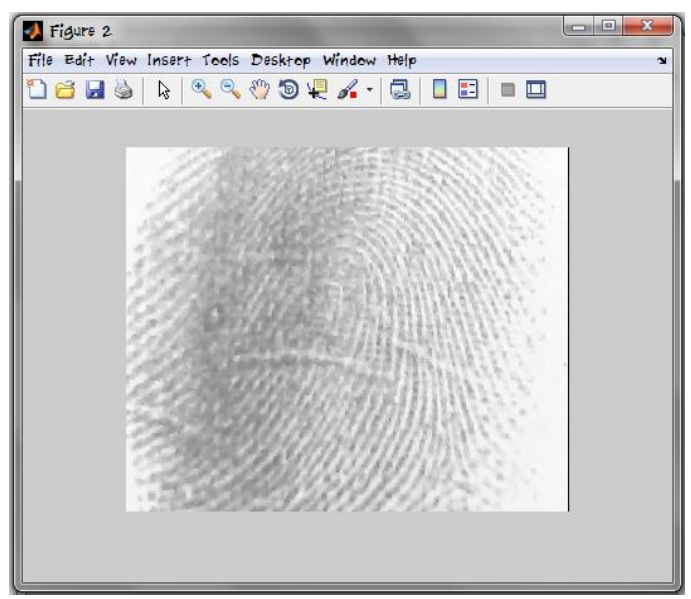

Gambar 8. Citra Input Hasil Grayscale

Gambar 9 menunjukkan citra yang sudah diubah dengan transformasi wavelet, dan Gambar 10 menunjukkan grafik histogram citra yang diolah. 


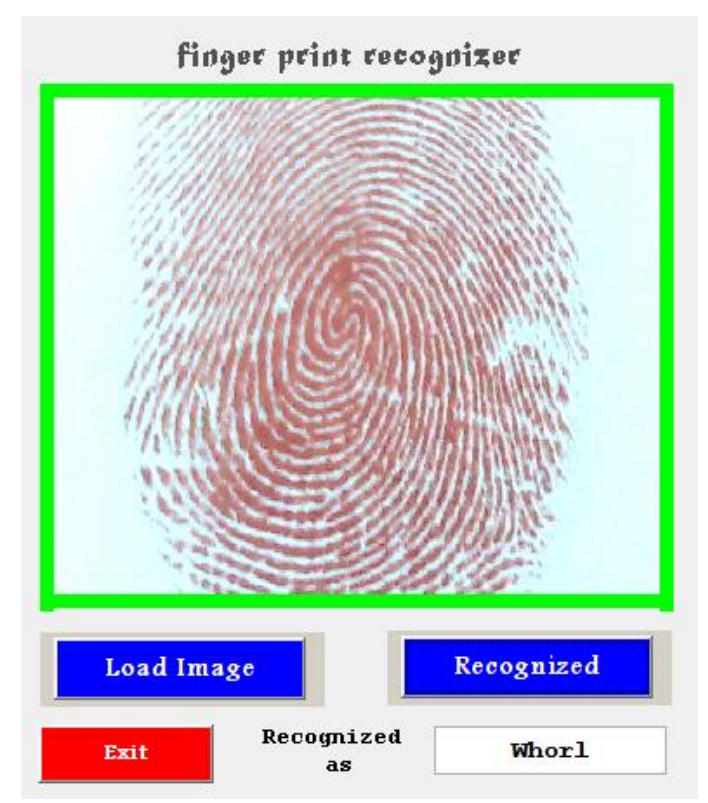

Gambar 9. Citra Input Hasil Grayscale dan Transformasi Wavelet

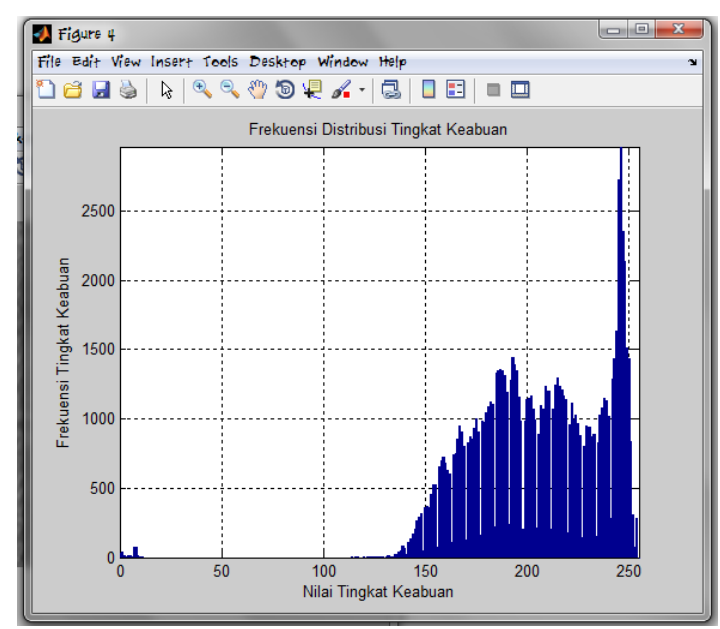

Gambar 10. Histogram Citra

\section{SIMPULAN}

Dari percobaan ini, dapat diambil kesimpulan bahwa mengidentifikasi tipe sidik jari manusia dengan menggunakan transformasi wavelet dapat melalui metode pemrograman Matlab yang telah diintegrasikan dengan GUI (Graphic user Interface) ataupun dengan metode manual untuk mengetahui tahapan dalam transformasi wavelet. Simulasi dengan Matlab dapat melalui tahapan input citra asli berupa gambar RGB, kemudian melakukan thresholding dan grayscale, dan selanjutnya melakukan tranformasi wavelet.

\section{DAFTAR PUSTAKA}

[1] F. Rahmah, "Image Smoothing Menggunakan Mean Filter untuk Perbaikan Kualitas Citra pada Pengujian Distorsi Kaca Spion," Jurnal Riset dan Aplikasi Matematika (JRAM), vol. 2, no. 1, 2018, doi: 10.26740/jram.v2n1.p41-49.

[2] F. Rahmah, A. Kusumawardhani, H. Setijono, A. M. Hatta, and. Irwansyah, "Radial line method for rear-view mirror distortion detection," in International Seminar on Photonics, Optics, and Its Applications (ISPhOA 2014), 2015, vol. 9444. doi: 10.1117/12.2080940.

[3] A. Mcandrew, "An Introduction to Digital Image Processing with Matlab Notes for SCM2511 Image Processing 1," 2004. [Online]. Available: https://fb.com/tailieudientucntt

[4] M. Palanca, G. Tozzi, and L. Cristofolini, "The use of digital image correlation in the biomechanical area: A review," International Biomechanics, vol. 3, no. 1. 2016. doi: 10.1080/23335432.2015.1117395.

[5] K. Padmavathi and K. Thangadurai, "Implementation of RGB and grayscale images in plant leaves disease detection - Comparative study," Indian Journal of Science and Technology, vol. 9, no. 6, 2016, doi: 10.17485/ijst/2016/v9i6/77739.

[6] N. D. Miranda, L. Novamizanti, and S. Rizal, "Convolutional Neural Network pada Klasifikasi Sidik Jari Menggunakan RESNET-50," Jurnal Teknik Informatika (Jutif), vol. 1, no. 2, 2020, doi: 10.20884/1.jutif.2020.1.2.18.

[7] V. S. Jabade, "Literature Review of Wavelet Based Digital Image Watermarking Techniques," 
International Journal of Computer Applications, vol. 31, no. 1, 2011.

[8] D. E. Pratiwi and A. Harjoko, "Implementasi Pengenalan Wajah Menggunakan PCA (Principal Component Analysis)," IJEIS (Indonesian Journal of Electronics and Instrumentation Systems), vol. 3, no. 2, 2013, doi: 10.22146/ijeis.3892. 